\title{
The overmethylated genes in Helicobacter pylori- infected gastric mucosa are demethylated in gastric cancers
}

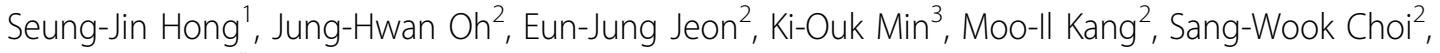 \\ Mun-Gan Rhyu ${ }^{1 *}$
}

\begin{abstract}
Background: The transitional-CpG sites between weakly methylated genes and densely methylated retroelements are overmethylated in the gastric mucosa infected with Helicobacter pylori (H. pylori) and they are undermethylated in the gastric cancers depending on the level of loss of heterozygosity $(\mathrm{LOH})$ events. This study delineated the transitional-CpG methylation patterns of CpG-island-containing and -lacking genes in view of the retroelements.

Methods: The transitional-CpG sites of eight CpG-island-containing genes and six CpG-island-lacking genes were semi-quantitatively examined by performing radioisotope-labelling methylation-specific PCR under stringent conditions. The level of $\mathrm{LOH}$ in the gastric cancers was estimated using the 40 microsatellite markers on eight cancer-associated chromosomes. Each gene was scored as overmethylated or undermethylated based on an intermediate level of transitional-CpG methylation common in the H. pylori-negative gastric mucosa.

Results: The eight CpG-island genes examined were overmethylated depending on the proximity to the nearest retroelement in the $\mathrm{H}$. pylori-positive gastric mucosa. The six CpG-island-lacking genes were similarly methylated in the H. pylori-positive and -negative gastric mucosa. In the gastric cancers, long transitional-CpG segments of the CpG-island genes distant from the retroelements remained overmethylated, whereas the overmethylation of short transitional-CpG segments close to the retroelements was not significant. Both the CpG-island-containing and -lacking genes tended to be decreasingly methylated in a LOH-level-dependent manner.

Conclusions: The overmethylated genes under the influence of retroelement methylation in the $\mathrm{H}$. pylori-infected stomach are demethylated in the gastric cancers influenced by $\mathrm{LOH}$.
\end{abstract}

\section{Background}

A mouse model infected with Helicobacter pylori (H. pylori) has illustrated that bone marrow stem cells migrate to the gastric mucosa and then they differentiate into gastric epithelial cells [1]. According to a selforganization model, highly expressed master genes can form a transcription hub to coordinate the expression of many other genes [2]. A dosage compensation mechanism proposes that there is an inverse correlation between the housekeeping genes containing CpG-islands and the tissue-specific genes lacking CpG-islands, which

\footnotetext{
* Correspondence: rhyumung@catholic.ac.kr

'Department of Microbiology, College of Medicine, The Catholic University of Korea, Seoul, Korea

Full list of author information is available at the end of the article
}

both share a limited amount of nuclear proteins in the nuclear space $[3,4]$. Both the self-organization and dosage compensation models highlight that the epigenetic co-regulation of highly active stomach-specific genes and weakly active housekeeping genes facilitates the trans-differentiation of marrow-derived cells in the stomach.

Individuals infected with $H$. pylori frequently undergo a series of gastric mucosal changes including precancerous and cancerous lesions [5]. Although CpG-island overmethylation that may result in the inactivation of cancer-associated genes is common in the H. pyloriinfected gastric mucosa, an association between the overmethylation and expression of individual CpGisland genes is ambiguous [6]. Gastric precancerous and
C Biomed Central

C 2010 Hong et al; licensee BioMed Central Ltd. This is an Open Access article distributed under the terms of the Creative Commons Attribution License (http://creativecommons.org/licenses/by/2.0), which permits unrestricted use, distribution, and reproduction in any medium, provided the original work is properly cited. 
cancerous lesions have shown CpG-island overmethylation as well as genome-wide undermethylation, but the two distinct methylation changes showed no cooperation for the sequential evolution of precancer and cancer [7]. In addition, the highly expressed stomachspecific genes playing a master role in the co-regulation of numerous genes have demonstrated a few methylation changes in the gastric cancers $[4,8]$. With respect to coordinate gene expression, it is necessary to delineate if the stomach-specific genes and the housekeeping genes undergo concurrent over- and under-methylation changes.

The retroelements are self-replicating parasitic DNAs that occupy half the human genome [9]. The host genome suppresses the hazardous mutation effect of the parasitic retroelements via a DNA methylation-dependent mechanism [10]. The transitional area between the weakly methylated genes and the densely methylated retroelements, such as the $\mathrm{CpG}$-island margin and the transcription start site lacking CpG-islands, is methylated to various degrees in a tissue-type-dependent manner $[4,11,12]$. The methylation of transitional-CpG sites changes dynamically in response to the trans-differentiation of bone marrow stromal cells and the loss-of-heterozygosity (LOH) events in gastric cancers [12-15]. Another previous study also has described that the "CpG-island shore" is related with the regulation of cell differentiation and carcinogenesis [16]. Interestingly, many transitional-CpG sites and gene-adjacent retroelements are simultaneously over- or undermethylated in a given tissue [11,17], indicating that the concurrent methylation changes in numerous genes are under the influence of retroelement methylation. Meanwhile, most CpG-rich islands are weakly methylated or unmethylated in most tissue types, and the CpG-rich sites are not suitable for the analysis of dynamic methylation adjacent to gene-control regions $[12,13,15,18]$. Therefore, the transitional-CpG sites, rather than CpG-rich islands, are likely to serve as pivot-methylation positions that reflect the concurrent methylation patterns associated with $H$. pylori infection and the evolution of cancer.

This study investigated the transitional-CpG methylation patterns of the CpG-island genes and the stomachspecific genes lacking CpG-islands in $H$. pylori-infected gastric mucosa and gastric cancers. The variable methylation of transitional-CpG sites was semi-quantitatively estimated under stringent methylation-specific PCR (MSP) conditions that produced clear DNA bands $[4,8]$. An increase or decrease in the transitional-CpG methylation of each gene was determined based on an intermediate methylation in the $H$. pylori-negative gastric mucosa.

\section{Methods}

\section{Collection of tissue samples}

Non-cancerous tissue samples were collected from the consecutive outpatients who underwent gastric endoscopy from April 2008 to October 2009 at St. Paul's Hospital, The Catholic University of Korea. During endoscopic examination, two adjacent tissue samples were obtained from the stomach antrum and body portion, respectively. One biopsy specimen was fixed with formalin for the histologic examination and the other biopsy specimen was used for DNA extraction. The pathologist confirmed a gastric epithelial cell content of more than $80 \%$ purity in the biopsy tissues. H. pylori infection was examined using the Warthin-Starry silver impregnation method. This study included 50 antrum and body pairs in $H$. pylori-negative cases with a mean age of 53.2, and 50 antrum and body pairs in $H$. pyloripositive cases with a mean age of 55.6. There were 25 males and 25 females in the $H$. pylori-negative cases and 26 males and 24 females in the H. pylori-positive cases. The gastric cancer tissues were obtained from the pathologic specimens of 48 male and 22 female patients (mean age: 63.7), who underwent surgical resection between March 2005 and December 2008 at St. Paul's Hospital, The Catholic University of Korea. The clinicopathologic tumor stage was determined according to the Tumor-Node-Metastasis (TNM) criteria [19]. All the subjects provided their written informed consent and this study was approved by the institutional review board.

\section{Tissue preparation and bisulfite modification of DNA}

The fresh biopsy specimens were used for feasible semiquantitative MSP analysis, because formalin-fixed tissue DNAs tend to be poorly amplified after bisulfite modification [8]. For the microsatellite analysis, the DNA was extracted from the formalin-fixed paraffin-embedded tumor tissues as described previously [20,21]. The tumor specimens were microdissected using a surgical scalpel under a stereomicroscope. All of the microdissected cancer tissues contained a cancer cell content of more than $80 \%$. Using DNA extraction buffer $(0.5 \%$ Tween-20, $1 \mathrm{mM}$ EDTA pH 8.0, $50 \mathrm{mM}$ Tris $\mathrm{pH}$ 8.0, $0.5 \mathrm{mg} / \mathrm{mL}$ proteinase $\mathrm{K}$ ), the biopsy specimens and microdissected tissues were digested at $37^{\circ} \mathrm{C}$ for $24 \mathrm{hr}$. Approximately 1,000 cells were incubated with $20 \mu \mathrm{L}$ of the DNA extraction buffer after which a DNA isolation kit (A1120, Promega, Madison, WI, USA) was used to extract the genomic DNA according to the manufacturer's instructions.

Tissue DNA was modified using sodium bisulfite as described elsewhere [8,11-13]. Briefly, $1 \mu \mathrm{g}$ genomic DNA was treated with $10 \mu \mathrm{L}$ of $3 \mathrm{M} \mathrm{NaOH}$ for $15 \mathrm{~min}$ 
at $37^{\circ} \mathrm{C}$. Then the denatured DNA was mixed with 1.04 $\mathrm{mL}$ of $2.3 \mathrm{M}$ sodium bisulfite and $60 \mu \mathrm{L}$ of $10 \mathrm{mM}$ hydroquinone and this was warmed at $50^{\circ} \mathrm{C}$ for $12 \mathrm{hrs}$. The bisulfite treated DNA, which was purified using Wizard DNA purification resin (Promega, Madison, WI, USA), was desulfonated with $3 \mathrm{M} \mathrm{NaOH}$ and precipitated with ethanol, and then was dissolved in $35 \mu \mathrm{L}$ of $5 \mathrm{mM}$ Tris buffer ( $\mathrm{pH} 8.0)$.

\section{Radioisotope-labelling semiquantitative methylation analysis}

Comparative analysis of the microarray and SAGE (Serial Analysis of Gene Expression) data has found that the number of transcripts counted in the SAGE data accurately represents a great difference in the gene activity between the stomach-specific genes and housekeeping genes [4]. The transitional-CpG sites of the stomach-specific genes (PGA5 and PGC) [22], the mucosa-healing genes (TFF1 and TFF2) [23], the cancer-related genes (CDH1, MLH1, PPARG, CDKN2A and RUNX3) [15,24-27], and the non-gastric genes (ARRDC4, DUSP6, TRAPPC2L , $M S L N$ and KRT6A) [28-32] were selected (Table 1). The MSP sites, sequences, and conditions are shown in Additional File 1. A low GC content and a repetitive sequence in the methylation-variable transitional-CpG site often showed weak or smearing MSP bands due to the reduced complexity of the nucleotide sequences following bisulfite treatment $[4,8,33]$. In order to increase the specificity of transitional-CpG amplification, each MSP primer set was designed to contain 3-5 CpG sites and to encompass a small amplicon size, and the MSP reaction was conducted under stringent conditions with using dTTP-radioisotope as described previously $[4,8,11,12]$. Briefly, $10 \mu \mathrm{L}$ of a PCR mixture that contained $1 \mu \mathrm{L}$ bisulfite modified DNA, $1 \mu \mathrm{Ci}$ of $\alpha{ }^{32} \mathrm{P}$ dTTP (PerkinElmer, Boston, MA, USA), $62.5 \mu \mathrm{M}$ dATP, dCTP and dGTP, $25 \mu \mathrm{M}$ dTTP, 1 pmol of primers, $0.1 \%$ Tween 20 and 0.3 unit of Taq polymerase was amplified by 32 PCR cycles under hot-start PCR conditions. The representative methylation results are shown in Figure 1A.

\section{Semiquantitative evaluation of transitional-CpG methylation variation}

The PCR condition of each MSP primer set was validated by plotting the standard curve according to various mixtures of band intensity from the MSP products with universal methylated and unmethylated control DNA $[11,18]$. The genomic DNA treated with DNA methylase (CpGenome Universal Methylated DNA, Chemicon, Temecula, CA, USA) and amplified by a universal primer (5'-CCG ACT CGA GNN NNN NAT GTG G-3') were used for the universal methylated and unmethylated control DNA, respectively. Based on the standard curve, the methylation density of the transitional-CpG site was calculated using the following formula: methylation proportion $(\%)=$ (methylation intensity/(methylation + unmethylation intensity) $) \times 100$ $[8,11,13,15,18]$. To validate the reproducibility of the variable methylation density using a semiquantitative analysis, the 5-level classification with $20 \%$-methylation increment and the 10-level classification with $10 \%$ methylation increment were compared in the paired tissue samples. The comparative analysis of the paired samples was conducted using the duplicated DNAs of the 40 tissues and 48 pairs of 1 -cm-adjacent tissues in addition to 100 pairs of antrum and body tissues that

Table 1 The nearest retroelement and the transcription of the 14 selected genes with and without CpG islands

\begin{tabular}{|c|c|c|c|c|}
\hline \multirow[t]{2}{*}{ Gene } & \multirow[t]{2}{*}{ CpG islands } & \multicolumn{2}{|c|}{ Nearest retroelement } & \multirow[t]{2}{*}{ No. of expressed transcripts in the stomach } \\
\hline & & Name of family & Distance to transcription start site & \\
\hline $\mathrm{CDH1}$ & Yes & Alu & $0.3 \mathrm{~kb}$ & 19 \\
\hline ARRDC4 & Yes & Alu & $1.7 \mathrm{~kb}$ & 7 \\
\hline PPARG & Yes & Alu & $2.3 \mathrm{~kb}$ & 3 \\
\hline CDKN2A & Yes & LTR & $2.4 \mathrm{~kb}$ & 1 \\
\hline TRAPPC2L & Yes & Alu & $3.8 \mathrm{~kb}$ & 14 \\
\hline DUSP6 & Yes & Alu & $6.6 \mathrm{~kb}$ & 8 \\
\hline MLH1 & Yes & Alu & $6.6 \mathrm{~kb}$ & 0 \\
\hline RUNX3 & Yes & LTR & $8.3 \mathrm{~kb}$ & 0 \\
\hline PGA5 & No & Alu & $1.2 \mathrm{~kb}$ & 734 \\
\hline$P G C$ & No & Alu & $1.6 \mathrm{~kb}$ & 33 \\
\hline TFF1 & No & Alu & $0.5 \mathrm{~kb}$ & 11 \\
\hline TFF2 & No & L1 & $2.7 \mathrm{~kb}$ & 632 \\
\hline MSLN & No & Alu & $1.4 \mathrm{~kb}$ & 50 \\
\hline KRT6A & No & Alu & $4.2 \mathrm{~kb}$ & 1 \\
\hline
\end{tabular}

The information concerning $\mathrm{CpG}$ islands, retroelements and the number of expressed transcripts in the stomach was obtained from previously published data [4]. 


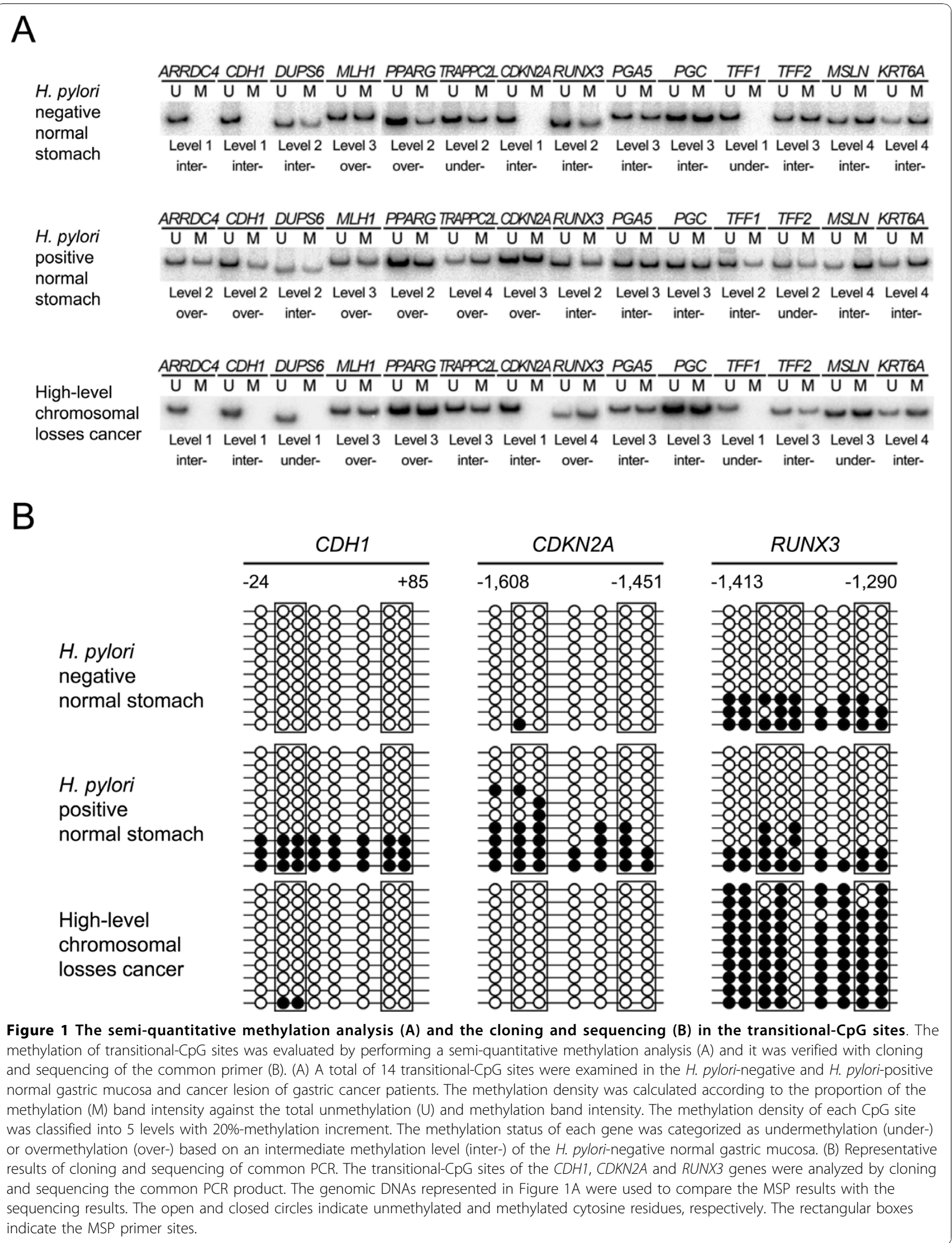




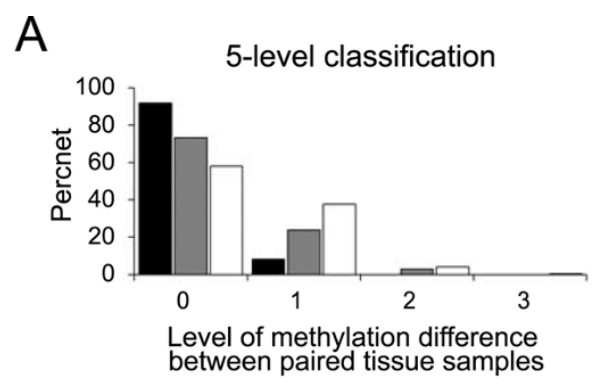

C

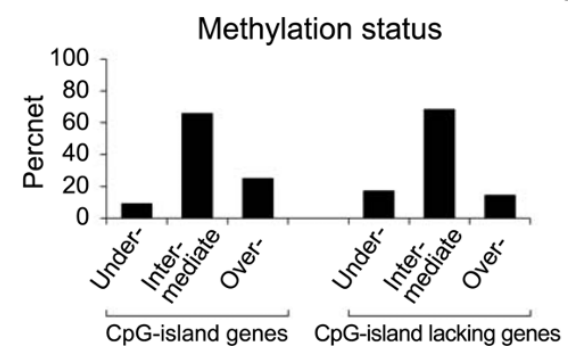

B

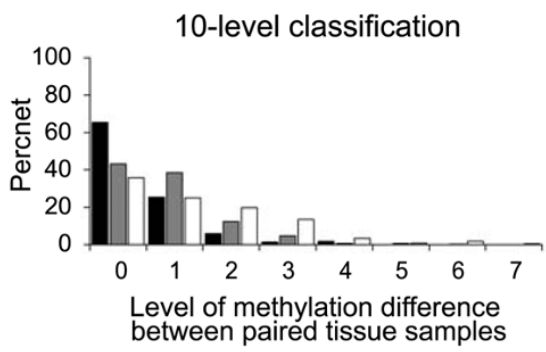

D

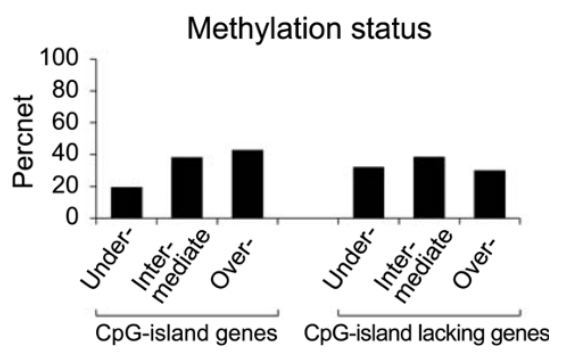

Figure 2 Analysis of variable methylation in the transitional-CpG sites. (A and B) The reproducibility of the 5-level classification with 20\%methylation increment (A) and 10-level classifications with 10\%-methylation increment (B) was verified by the proportion of the paired tissue samples showing no differences in the level of methylation. The duplicated DNAs of the same tissue (closed bars), a pair of 1-cm-adjacent tissues (grey bars) and a pair of antrum and body tissues (open bars) were compared. (C and D) Analysis of an intermediate methylation level. The frequency of undermethylated and overmethylated cases was estimated based on an intermediate level spanning two levels (20\% methylation) (C) and one level (10\% methylation) (D) of 10-level classification common in H. pylori-negative gastric mucosa.

were obtained from the $50 \mathrm{H}$. pylori-negative stomach tissues and the $50 \mathrm{H}$. pylori-positive stomach tissues (Figure 2).

The overmethylation rate of each transitional-CpG site in the $H$. pylori-positive and -negative gastric mucosa was calculated by the relative proportion of overmethylated cases to the total sum of the over- and under-methylated cases. The H. pylori-associated overmethylation rate was calculated using the $H$. pylori-positive-to-negative ratio of each transitional-CpGovermethylation rate. This was used to evaluate the relationship between the methylation of transitionalCpG sites and the distance between the transcription start site and the nearest retroelement (Figure 3).

\section{Cloning and sequencing of methylation-variable site}

The MSP results of transitional-CpG sites were reconfirmed with cloning and sequencing of the common PCR primer sets encompassing both the unmethylated and methylated CpG sites (Figure 1B) $[4,11,12]$. The PCR products of the common primer sets were cloned into the T\&A cloning vector (Real Biotech, Taipei, Taiwan). The DNA sequencing was performed for 10 clones of the common PCR vectors using the BigDye Termination Kit (PE Biosystems, Foster City, CA, USA) and an ABI automated DNA sequencer (PE Biosystmes,
Warrington, UK). Because the common primer sets covering the $\mathrm{CpG}$-poor regions produced various degrees of methylation according to the PCR condition, we adjusted the PCR condition of the common primer set to obtain the methylation density that was similar in both the semi-quantitative MSP assay and the sequencing results of the 10 common-PCR clones.

\section{Analysis of microsatellite alleles}

For the PCR-based LOH analysis, a total of 40 microsatellite markers on eight cancer-associated chromosomes (3p, 4p, 5q, 8p, 9p, 13q, 17p and 18q) and the guidelines for scoring the status of $\mathrm{LOH}$ and MSI were used as described elsewhere $[20,21]$. The allelic profile of the 40 microsatellite sequences examined in each case was initially categorized into MSI based on the presence of novel alleles in the homozygous marker and the unilateral allelic loss in the heterozygous marker. According to the number of the LOH-positive chromosomes, the level of $\mathrm{LOH}$ was scored as low-level (two or three chromosomal losses, LOH-L) and high-level (four or more chromosomal losses, LOH-H) LOH. One or no chromosomal losses were classified into the baselinelevel ( $\mathrm{LOH}-\mathrm{B})$ for the diffuse-type cancer and into the low level for intestinal and mixed type, respectively, depending on their corresponding histological subtype. 

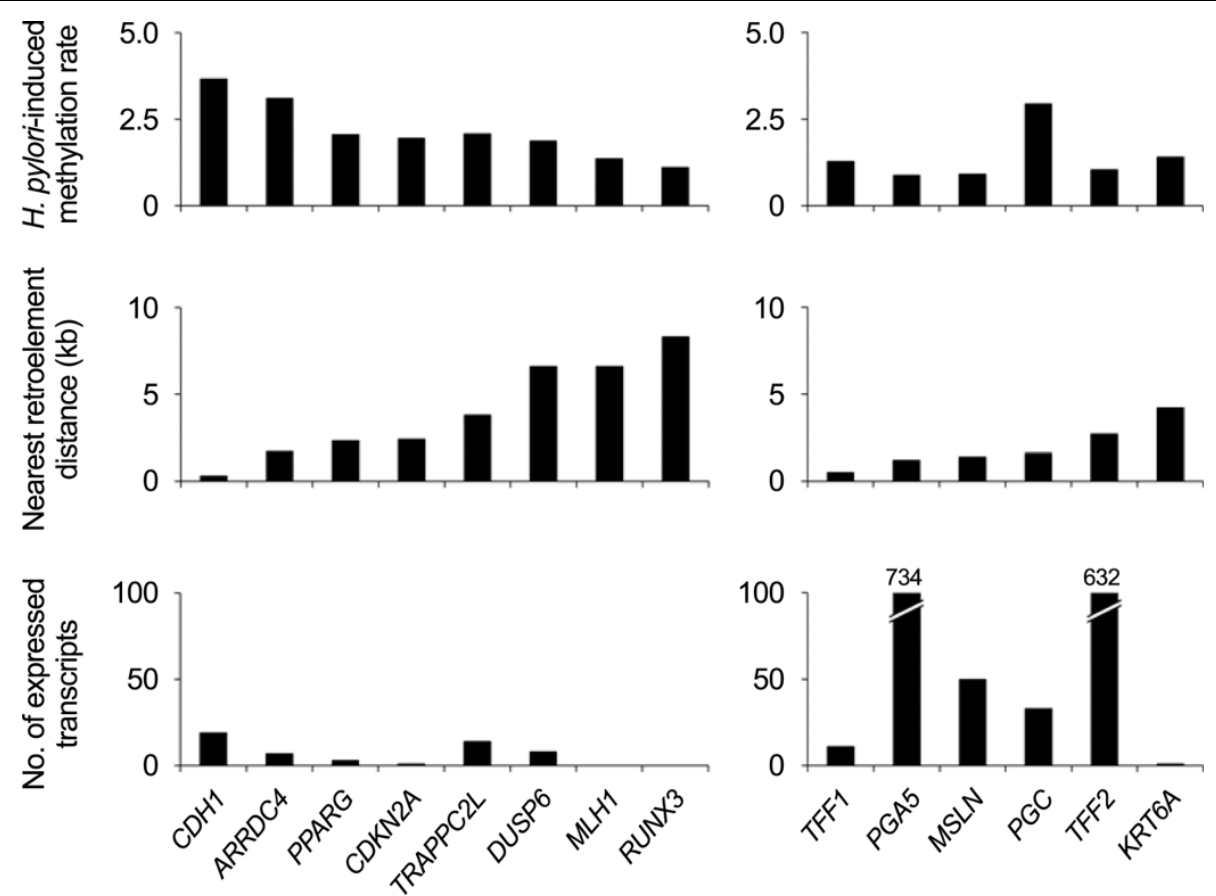

Figure $3 \mathrm{H}$. pylori-induced methylation of the CpG-island-containing and -lacking genes according to the distance to the nearest retroelements and the transcription activity. A total of 14 transitional-CpG sites were grouped into eight CpG-island genes (CDH1, ARRDC4, PPARG, CDKN2A, TRAPPC2L, DUSP6, MLH1 and RUNX3) and six genes lacking CpG-islands (PGA5, PGC, TFF1, TFF2, MSLN and KRT6A). The generetroelement distance was estimated between the transcriptional start sites and the nearest Alu, L1 or LTR retroelements. The H. pylori-induced methylation rate was represented by the $\mathrm{H}$. pylori-positive-to-negative ratio of the overmethylation rate. The overmethylation rate was calculated according to the relative proportion of overmethylated cases to the total sum of the over- and under-methylated cases. The transcriptional activity of each gene was shown with the number of expressed transcripts [4].

\section{Statistical analysis}

Fisher's exact test was used for comparing the over- and under-methylation changes between the $H$. pylori-negative or -positive gastric mucosa and the gastric cancers, with significance assigned to values below $P$ values less than 0.01 . The Student's $t$ test was used for comparing the methylation differences between the gastric noncancerous and cancerous tissues, with significance assigned to values below $P$ values less than 0.05 . Statistical evaluation was performed by using the statistical software package SPSS 11.0 (SPSS Inc., Chicago, IL, USA).

\section{Results}

\section{Methylation-variation in noncancerous tissues}

A total of 14 transitional-CpG sites were chosen from eight CpG-island genes (CDH1, ARRDC4, PPARG, CDKN2A, TRAPPC2L, DUSP6, MLH1 and RUNX3) and six CpG-island-lacking genes (PGA5, PGC, TFF1, TFF2, $M S L N$ and KRT6A) (Table 1). The reproducibility of transitional-CpG site amplified by each MSP primer set was evaluated with the duplicated DNAs of the same tissue, a pair of 1-cm-adjacent tissues and a pair of antrum and body tissues (Figure $2 \mathrm{~A}$ and $2 \mathrm{~B}$ ). $92 \%$ of the 40 duplicated DNAs, $73 \%$ of the 481 -cm-adjacent tissue pairs, and $58 \%$ of the 100 antrum and body pairs were scored as the same methylation levels in the 5level classification. The same-scored cases of the duplicated experiments were approximately $25 \%$ more frequent in the 5-level classification than in the 10-level classification.

An intermediate level of variable transitional-CpG methylation was analyzed using 1,400 MSP amplicons of the 14 transitional-CpG sites obtained from 100 $H$. pylori-negative stomach samples (Figure 2C and 2D). In the 10-level classification, the fraction of a single common methylation level (38\%) was so low that an intermediate level was determined based on two common levels. 937 (67\%) of the 1,400 MSP amplicons were categorized into an intermediate level in the 100 tissues. Intermediate methylation levels of eight CpG-island margins tended to be lower than those of six CpGisland-lacking sites (Table 2). Overall, large fractions of individual stomach tissues (67\%) and 1-cm-adjacent tissue pairs (73\%) showed that the transitional-CpG sites were methylated in a range of similar densities varying between about $20 \%$. Therefore, an intermediate level spanning two levels (20\% methylation) of 10-level classification was used to determine the over- or under- 
Table 2 The frequency of under- and over-methylated cases as determined based on intermediate methylation levels common in the $H$. pylori-negative gastric mucosa $(n=100)$

\begin{tabular}{|c|c|c|c|c|}
\hline Gene name & $\begin{array}{c}\text { Intermediate methylation } \\
\text { density }\end{array}$ & $\begin{array}{l}\text { No. of under-methylated } \\
\text { cases }\end{array}$ & $\begin{array}{l}\text { No. of intermediate } \\
\text { methylation cases }\end{array}$ & $\begin{array}{c}\text { No. of over-methylated } \\
\text { cases }\end{array}$ \\
\hline \multicolumn{5}{|c|}{$\begin{array}{l}\text { CpG-island containing } \\
\text { genes }\end{array}$} \\
\hline $\mathrm{CDH1}$ & $0-20 \%$ & 0 & 79 & 21 \\
\hline ARRDC4 & $0-20 \%$ & 0 & 80 & 20 \\
\hline PPARG & $0-20 \%$ & 0 & 60 & 40 \\
\hline CDKN2A & $0-20 \%$ & 0 & 54 & 46 \\
\hline TRAPPC2L & $40-60 \%$ & 13 & 81 & 6 \\
\hline DUSP6 & $20-40 \%$ & 26 & 62 & 12 \\
\hline MLH1 & $20-40 \%$ & 20 & 61 & 19 \\
\hline RUNX3 & $30-50 \%$ & 5 & 53 & 42 \\
\hline \multicolumn{5}{|c|}{$\begin{array}{l}\text { CpG-island lacking } \\
\text { genes }\end{array}$} \\
\hline PGA5 & $40-60 \%$ & 10 & 78 & 12 \\
\hline$P G C$ & $40-60 \%$ & 29 & 67 & 4 \\
\hline TFF1 & $20-40 \%$ & 11 & 52 & 37 \\
\hline TFF2 & $30-50 \%$ & 36 & 60 & 4 \\
\hline MSLN & $60-80 \%$ & 0 & 88 & 12 \\
\hline KRT6A & $60-80 \%$ & 17 & 65 & 18 \\
\hline
\end{tabular}

methylated status of transitional-CpG sites in the gastric mucosa.

\section{Relationship between $H$. pylori-associated} overmethylation either the retroelements or transcription activity

The frequencies of the over- and under-methylated cases were separately counted to estimate alterations in the variable methylation of the transitional-CpG sites (Table 3). On the analysis of the overmethylated cases, all the CpG-island margins were significantly overmethylated in the $H$. pylori-infected gastric mucosa and none of the CpG-island-lacking sites showed a significant difference for the frequency of the overmethylated cases. On the analysis of the undermethylated cases, the frequency of the undermethylated TFF1 gene was significantly low in the $H$. pylori-positive gastric mucosa $(P=$ $0.003)$. The methylation data of bone marrow was cited from a previous study using the same radioisotope-labeling MSP protocol [4]. In bone marrow, the PGC, TFF1, $M S L N$ and RUNX3 genes were completely methylated, whereas most of the CpG-island genes were completely unmethylated.

The relationship between the transitional-CpG methylation and the distance to the nearest retroelement was evaluated using the $H$. pylori-associated overmethylation rate (Figure 3 ). In the $\mathrm{CpG}$-island genes, the $H$. pyloriassociated overmethylation rate was higher as the distance of the nearest retroelement became shorter. The CpG-island-lacking genes that showed no significant methylation difference between the $H$. pylori-positive and -negative mucosa were methylated irrespective of the distance of the nearest retroelement.

The methylation of transitional-CpG sites was compared between the stomach and bone marrow in terms of the transcription activity (Table 1 and Figure 4). The CpG-island gene group that was weakly active in the stomach was more methylated in the $H$. pylori-negative and -positive tissues than that in the bone marrow. Of the CpG-island-lacking TFF2 and PGA5 genes that were most highly expressed in the stomach, the mean methylation level of the TFF2 gene was lower than in the bone marrow (1.9) than in the $H$. pylori-negative $(2.6$, $P=0.015)$ and -positive mucosa $(2.7, P=0.015)$. The mean methylation level of the $P G A 5$ gene was similar in the bone marrow (3.1) and $H$. pylori-negative (3.0) and -positive mucosa (3.0). The PGC and TFF1 stomachspecific genes, which were weakly active in the gastric mucosa when compared with the two master stomachspecific genes, were densely methylated in bone marrow (mean methylation level, 4.3 and 4.8).

\section{Methylation patterns in the gastric cancer under the influence of $\mathrm{LOH}$}

The gastric cancers examined by PCR-based LOH analysis were categorized into baseline-level $\mathrm{LOH}(\mathrm{LOH}-\mathrm{B})$, low-level LOH (LOH-L), high-level LOH (LOH-H), and MSI as was reported previously $[20,21]$. Thirteen LOHB (19\%), 29 LOH-L (41\%), 24 LOH-H (34\%), and 4 MSI (6\%) cases were identified from 70 gastric cancer samples. Overall, the frequency of both the overmethylated genes with and without CpG-islands was significantly 
Table 3 Comparison of the frequency of over- and undermethylated genes detected in the gastric non-cancerous and cancerous tissues

\begin{tabular}{|c|c|c|c|c|c|c|c|}
\hline \multirow[t]{2}{*}{ Gene } & \multicolumn{2}{|l|}{ Noncancerous tissue } & \multicolumn{4}{|c|}{ Microsatellite genotype of gastric cancers (\%) } & \multirow{2}{*}{$\begin{array}{c}\text { Bone marrow } \\
\begin{array}{c}(\mathrm{n}=18) \\
(\%)\end{array}\end{array}$} \\
\hline & $\begin{array}{l}\text { H. pylori negative } \\
(\mathrm{n}=100)\end{array}$ & $\begin{array}{l}\text { H. pylori positive } \\
(\mathrm{n}=100)\end{array}$ & $\begin{array}{l}\text { LOH-B } \\
(n=13)\end{array}$ & $\begin{array}{l}\text { LOH-L } \\
(\mathrm{n}=29)\end{array}$ & $\begin{array}{l}\text { LOH-H } \\
(n=24)\end{array}$ & $\begin{array}{c}\text { MSI } \\
(n=4)\end{array}$ & \\
\hline \multicolumn{8}{|c|}{ Overmethylation frequency } \\
\hline $\mathrm{CDH} 1$ & 21 & $77^{*}$ & $0(0)^{*}$ & $7(24)$ & $3(13)$ & $0(0)$ & $0(0)$ \\
\hline ARRDC4 & 20 & $62^{*}$ & $3(23)$ & $8(28)$ & $1(4)^{*}$ & $1(25)$ & $0(0)$ \\
\hline PPARG & 40 & $82^{*}$ & $5(38)$ & $7(24)$ & $6(25)$ & $1(25)$ & $0(0)$ \\
\hline CDKN2A & 46 & $90^{*}$ & $9(69)$ & $16(55)$ & $9(38)$ & $2(50)$ & $4(22)$ \\
\hline TRAPPC2L & 6 & $21^{*}$ & $6(46)^{*}$ & $8(28)^{*}$ & $1(4)$ & $1(25)$ & $0(0)$ \\
\hline DUSP6 & 12 & $36^{*}$ & $3(23)$ & $3(10)$ & $1(4)$ & $2(50)$ & $0(0)$ \\
\hline MLH1 & 19 & $37^{*}$ & $4(31)$ & $17(59)^{*}$ & $11(46)$ & $3(75)$ & $0(0)$ \\
\hline RUNX3 & 42 & $85^{*}$ & $10(77)$ & $26(90)^{*}$ & $19(79)^{*}$ & $4(100)$ & $18(100)$ \\
\hline PGA5 & 12 & 13 & $5(38)$ & $8(28)$ & $1(4)$ & $0(0)$ & $0(0)$ \\
\hline$P G C$ & 4 & 10 & $4(31)$ & $4(14)$ & $5(21)$ & $1(25)$ & $18(100)$ \\
\hline TFF1 & 37 & 52 & $5(38)$ & $3(10)^{*}$ & $3(13)^{*}$ & $0(0)$ & $18(100)$ \\
\hline TFF2 & 4 & 3 & $4(31)$ & $4(14)$ & $1(4)$ & $0(0)$ & $2(11)$ \\
\hline MSLN & 12 & 11 & $8(62)^{*}$ & $16(55)^{*}$ & $6(25)$ & $1(25)$ & $18(100)$ \\
\hline KRT6A & 18 & 16 & $4(31)$ & $16(55)^{*}$ & $4(17)$ & $3(75)$ & $3(17)$ \\
\hline \multicolumn{8}{|c|}{ Undermethylation frequency } \\
\hline $\mathrm{CDH1}$ & 0 & 0 & $0(0)$ & $0(0)$ & $0(0)$ & $0(0)$ & $0(0)$ \\
\hline ARRDC4 & 0 & 0 & $0(0)$ & $0(0)$ & $0(0)$ & $0(0)$ & $0(0)$ \\
\hline PPARG & 0 & 0 & $0(0)$ & $0(0)$ & $0(0)$ & $0(0)$ & $0(0)$ \\
\hline CDKN2A & 0 & 0 & $0(0)$ & $0(0)$ & $0(0)$ & $0(0)$ & $0(0)$ \\
\hline TRAPPC2L & 13 & 11 & $1(8)$ & $2(7)$ & $7(29)$ & $1(25)$ & $16(89)$ \\
\hline DUSP6 & 26 & 25 & $3(23)$ & $13(45)$ & $12(50)$ & $2(50)$ & $18(100)$ \\
\hline MLH1 & 20 & 18 & $7(54)$ & $6(21)$ & $9(38)$ & $1(25)$ & $17(94)$ \\
\hline$R \cup N \times 3$ & 5 & 1 & $0(0)$ & $1(3)$ & $2(8)$ & $0(0)$ & $0(0)$ \\
\hline PGA5 & 10 & 14 & $0(0)$ & $3(10)$ & $5(21)$ & $0(0)$ & $0(0)$ \\
\hline$P G C$ & 29 & 18 & $4(31)$ & $8(28)$ & $5(21)$ & $2(50)$ & $0(0)$ \\
\hline TFF1 & 11 & $1^{*}$ & $7(54)$ & $19(66)^{*}$ & $17(71)^{*}$ & $3(75)$ & $0(0)$ \\
\hline TFF2 & 36 & 26 & $4(31)$ & $11(38)$ & $8(33)$ & $3(75)$ & $13(72)$ \\
\hline MSLN & 0 & 0 & $0(0)$ & $1(3)$ & $1(4)$ & $2(50)$ & $0(0)$ \\
\hline KRT6A & 17 & 16 & $3(23)$ & $3(10)$ & $3(13)$ & $1(25)$ & $5(28)$ \\
\hline
\end{tabular}

The gastric cancers were categorized into baseline-level LOH (LOH-B), low-level LOH (LOH-L), high-level LOH (LOH-H) and microsatellite instability (MSI). The details are described in the material and methods section.

${ }^{*} H$. pylori-positive gastric mucosa and gastric cancers were compared with $H$. pylori-negative gastric mucosa. Significant differences were determined using Fisher's exact test $(P<0.01)$

lower in the $\mathrm{LOH}-\mathrm{H}$ cases $(21 \%)$ than that in $\mathrm{LOH}-\mathrm{L}$ $(35 \%, P<0.0001)$ and LOH-B cases $(38 \%, P<0.0001)$. In comparison of the methylation levels in the noncancerous and LOH-B cancerous tissues, the CpG-island genes in the gastric cancers tended to be more methylated than those in the $H$. pylori-negative tissues and to be less methylated than those in the $H$. pylori-positive tissues (Figure 4). In analysis of the CpG-island-lacking genes, the mean methylation level of the TFF2 (3.1 vs. 2.6, $P=0.029)$ and PGA5 (3.5 vs. $3.0, P=0.035)$ master genes was high in the LOH-B cases compared with that of the $H$. pylori-negative tissue. Meanwhile, the mean methylation level of the TFF1 gene was low in the
LOH-B cases compared with the $H$. pylori-positive cases (1.8 vs. $2.6, P=0.024)$.

On the analysis of four CpG-island genes located within a $3-\mathrm{kb}$ distance to the nearest retroelements (CDH1, ARRDC4, PPARG and CDKN2A) (Figure 5A), the frequency of overmethylated genes was significantly low in the gastric cancers (LOH-B, 33\%, $P<0.0001$; LOH-L, 33\%, $P<0.0001$; LOH-H, 20\%, $P<0.0001$ ) when compared with the $H$. pylori-positive gastric mucosa (78\%). The TRAPPC2L, DUSP6, MLH1 and RUNX3 genes more than 3 -kb distal from the nearest retroelements were similarly overmethylated in the $H$. pylori positive mucosa (43\%) and gastric cancers $(\mathrm{LOH}-$ 


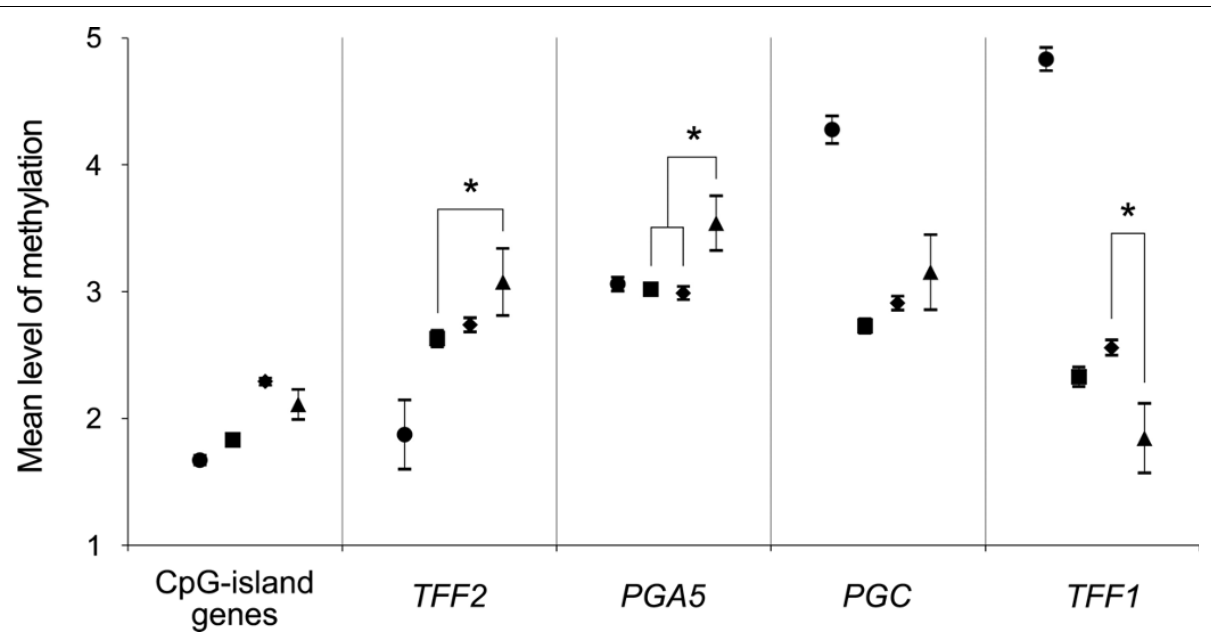

Figure 4 The methylation in the bone marrow and the gastric noncancerous and cancerous tissues. The mean level of methylation in the bone marrow $(\bullet)$, the H. pylori-negative gastric mucosa $(\boldsymbol{\bullet})$, the H. pylori-positive gastric mucosa $(\bullet)$ and the baseline-level LOH cases $(\mathbf{\bullet})$ was compared. Asterisks indicate significant differences between the noncancerous stomach tissues and the baseline-level LOH cancers $(P<$ 0.05). Student's $t$ test was used. Error bars indicate the standard error of the mean.

B, 44\%; LOH-L, 47\%; LOH-H, 33\%) (Figure 5B). On the analysis of the CpG-island-lacking gene group (Figure $5 \mathrm{C})$, the overmethylated genes were significantly frequent in the LOH-B (37\%, $P=0.015$ and 0.006$)$ and LOH-L $(29 \%, P=0.001$ and $<0.0001)$ cases when compared with that of the $H$. pylori-positive $(18 \%)$ and H. pylori-negative (15\%) mucosa.

Of the 14 genes that were examined, the TFF1 gene closest to the retroelements was undermethylated in the gastric cancers irrespective of the LOH level (Figure 3 and Table 3). On the contrary, the MHL1, RUNX3 and KRT6A genes that showed few transcripts were far away from the retroelements and they were frequently overmethylated in the LOH-L cases (Table 1 and Table 3). The number of MSI cases detected in this study was not enough to be statistically analyzed for the methylation changes. However, the frequency of the overmethylated genes distant from the nearest retroelements was highest in the MSI cases (Table 3 and Figure 5B).

\section{Discussion}

A comparative analysis of the whole transcripts between bone marrow and somatic tissues has illustrated that the CpG-island-containing and -lacking gene groups are expressed predominantly in pluripotent stem cells and somatic tissues inducing non-dividing terminal differentiation, respectively $[4,12]$. In particular, there is a great difference in the number of SAGE transcripts between the highly expressed master-specific gene group and weakly active housekeeping gene group in the stomach (Table 1) [4,12]. The H. pylori-infected gastric mucosa that promotes the recruitment of bone marrow stem cells has been associated with the overmethylation and down-regulation of $\mathrm{CpG}$-island genes, which paves the way for the non-dividing terminal differentiation of the newly fixed stem cells [4]. In this study, all of the eight CpG-island genes and none of the six CpG-island-lacking genes were overmethylated in the $H$. pylori-infected mucosa (Table 3). This agrees with a previous study [4] reporting that the inverse relationship between the overmethylated CpG-island genes and the non-overmethylated stomach-specific genes lacking CpG-islands in a nuclear space facilitates the high expression of stomachspecific genes for the stomach-specific terminal differentiation of marrow-derived stem cells (Figure 6).

There are three major retroelements in the human genome, Alu, L1, and LTR, of which Alu copies are short in size and enriched in close proximity to the CpG-island genes (Table 1) [11]. The extent of CpGislands is closely related to the distance between the host genes and the parasitic retroelements [11]. In this study, the CpG-island genes containing a short transitional-CpG segment close to the Alu elements were more frequently overmethylated than those containing a long transitional-CpG segment distant from the Alu elements in the H. pylori-positive gastric mucosa (Figure 3). A previous study on the trans-differentiation of marrow and adipose stem cells has also shown that the adipocyte differentiation of marrow stem cells results in the overmethylation of short transitional-CpG segments of the PPARG and CDKN2A genes but not long transitional-CpG segments of the $M L H 1$ and $R U N X 3$ genes [13]. It is likely that the gene-adjacent retroelements are associated with the concurrent overmethylation of numerous $\mathrm{CpG}$-island genes in a distance-dependent manner, and this regulates the patterning of DNA 


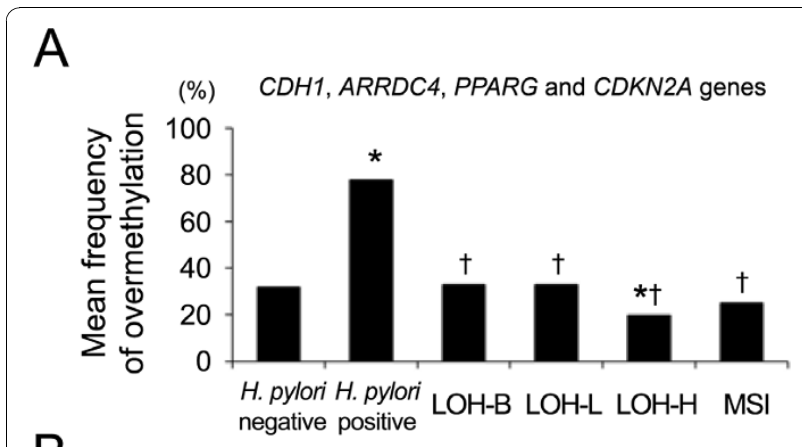

B

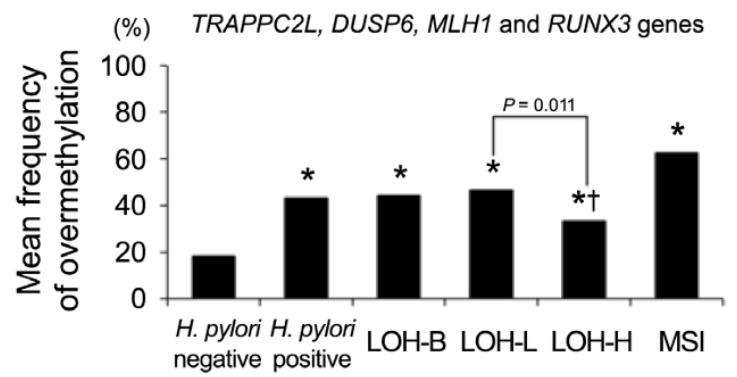

C

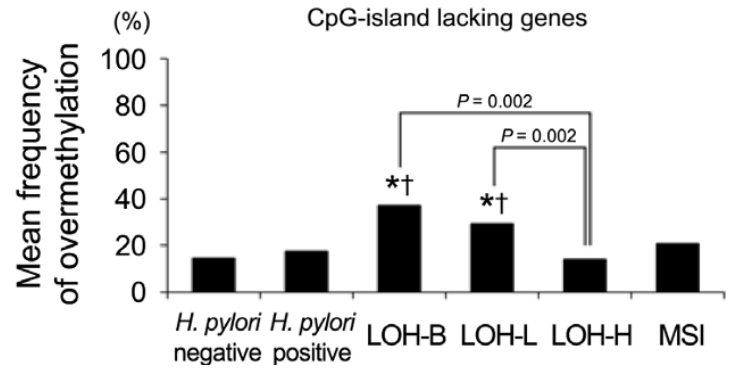

Figure 5 The frequency of overmethylated cases was compared between the gastric noncancerous and cancerous tissues. A total of 14 genes that were examined were grouped into three categories: (A) CpG-island-containing genes less than 3-kb close to the nearest retroelement; (B) CpG-island-containing genes more than 3-kb distant from the nearest retroelement; (C) The PGA5, PGC, TFF1, TFF2, MSLN and KRT6A genes. The asterisks and crosses indicate significant differences compared with the $H$. pylori negative and $H$. pylori positive gastric mucosa, respectively $(P<0.05)$. Student's $t$ test was used.

methylation for the maintenance of both the highly expressed stomach-specific genes and the weakly expressed housekeeping genes. Therefore, the length of transitional-CpG sites is considered as a DNA methylation code that modulates the tissue-specific terminal-differentiation of marrow-derived stem cells [4].

Both the CpG-island-positive and -negative genes tended to be demethylated in a $\mathrm{LOH}$-level-dependent manner, which was consistent with the previous reports $[15,18]$. The CpG-island genes in close proximity to the retroelements were undermethylated in gastric cancers when compared with that in the H. pylori-positive gastric mucosa, whereas the $\mathrm{CpG}$-island genes distant from the retroelements were similarly overmethylated in the gastric cancers and H. pylori-positive mucosa (Figure 5). A previous study on marrow and adipose stem cells has also shown that short transitional-CpG segments are over- or undermethylated more dynamically than long transitional-CpG segments in response to trans-differentiation induction as well as $\mathrm{H}_{2} \mathrm{O}_{2}$ treatment [13]. Short transitional-CpG segments close to the retroelements that are readily overmethylated in the $H$. pylori-positive mucosa appear to be promptly demethylated with the LOH events (Figure 6).

When considering that the nuclear proteins binding to a gene-control region prevent the methylation spreading of parasitic retroelements [34], the transitional-CpG sites reflect a balance between the methylation spreading and transcriptional activity. In cancer tissue that undergoes the $\mathrm{LOH}$ event that reduces a gene dose, the remaining gene copies have the increased possibility of using the nuclear proteins and this would lead to the demethylation of transitional-CpG segments $[3,4,12]$. Previous studies have described the undermethylation and up-regulation of housekeeping genes in various types of invasive and migratory cells and tissues, such as embryo implantation, invasive placentation, stem cell migration, and cancer progression $[4,35]$. The dose-compensatory demethylation in gastric cancer appears to facilitate the interruption of non-dividing terminal-differentiation of newly fixed stem cells and to reactivates a stem-cell intrinsic program for cell migration and proliferation (Figure 6) [36].

Of the four CpG-island-lacking stomach-specific genes, TFF2, PGA5, PGC and TFF1, the TFF2 gene was undermethylated in bone marrow when compared with that of the gastric mucosa (Figure 4). The two stomachspecific genes (PGA5 and TFF2) were most highly expressed in the gastric mucosa (Table 1). The PGA5 gene was similarly methylated in bone marrow and gastric mucosa. The expression of the PGC and TFF1 genes that were densely methylated in bone marrow was relatively weak in the gastric mucosa (Table 1). Assuming the fixation of bone marrow derived stem cells in the gastric mucosa, the expression pattern of the four stomach-specific genes was consistent with their methylation patterns in bone marrow. According to a selforganization model [2], the stomach tissue-environment induces the high expression of master genes nucleating a transcription hub that recruits other many genes and nuclear proteins for gastric cell proliferation and differentiation (Figure 6). The methylation pattern of the four genes was similar in the $\mathrm{H}$. pylori-positive and -negative gastric mucosa (Figure 4), and this implicates the coordinate expression of stomach-specific genes that initiate the adaptation of marrow-derived stem cells to the stomach tissue environment. 


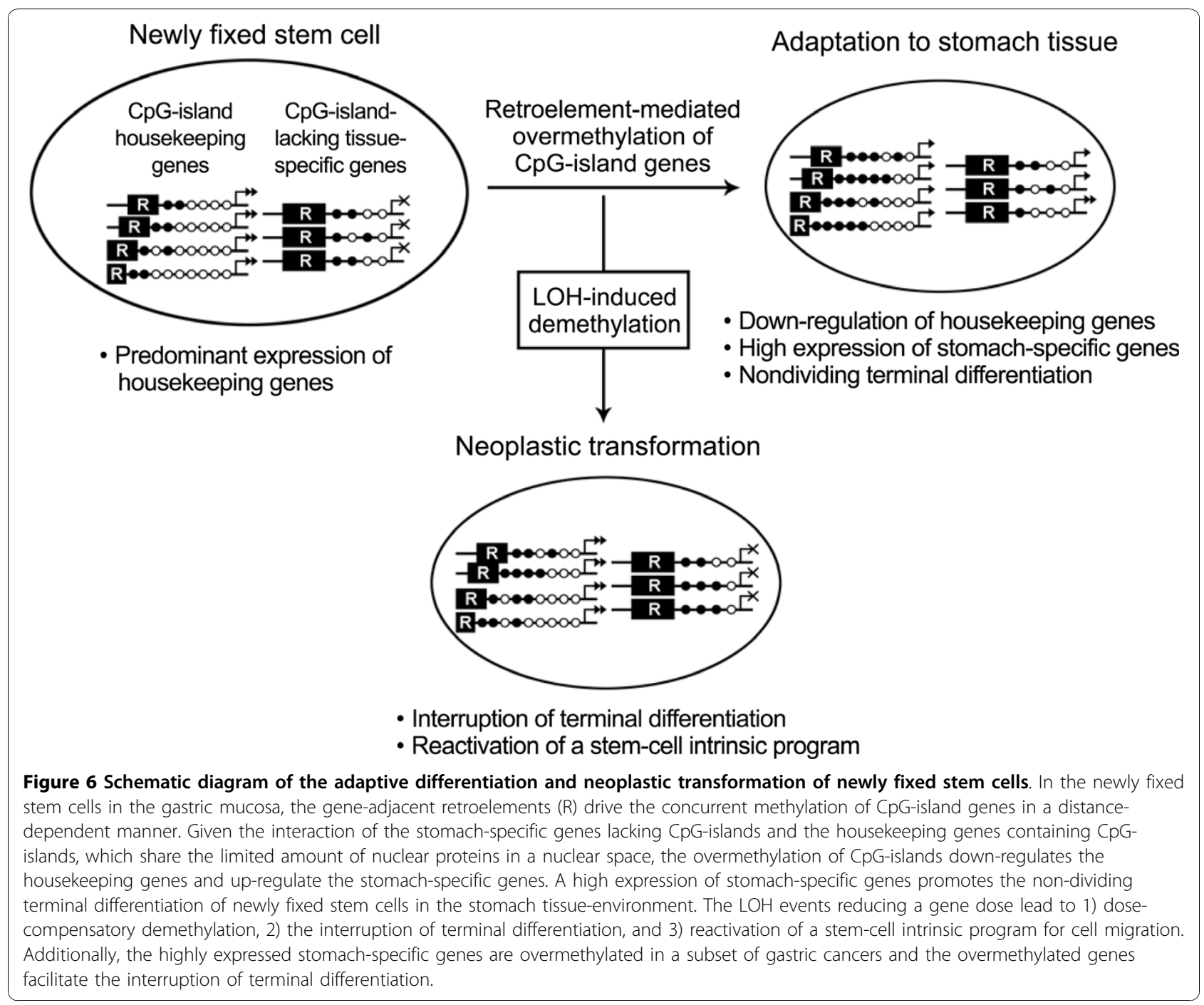

Even though the master stomach-specific genes and retroelements sustain the high-fidelity replication of concurrent methylation patterns, erroneous DNA methylation that is more common than erroneous DNA base sequences often gives rise to the aberrantly methylated genes [37,38]. The TFF2 and PGA5 master genes were found to be densely methylated in the LOH-B cases (Figure 4). The LOH-B cases having a few $\mathrm{LOH}$ events are likely to preserve the methylation pattern formed in cancer progenitor cells. In addition, the TFF1 gene in close proximity to the retroelement was undermethylated in gastric cancers (Table 3). This discordant methylation pattern of the stomach-specific genes may be improper to maintain a transcription hub in the stomach tissue-environment and to induce the non-dividing terminal differentiation of newly fixed stem cells (Figure 6).

Comparison of the H. pylori-positive and -negative gastric cancer tissue was not conducted, because the methylation status of the CpG-islands in the gastric cancerous and precancerous lesions has been found to be similar in the $H$. pylori-infected and non-infected patients [7]. In this study, the transitional-CpG sites in diffusetype gastric cancers tended to be overmethylated in the LOH-B cases and to be undermethylated in the LOH-H genotype cases depending on the level of chromosomal losses. Additionally, both the over- and under-methylation frequencies of individual and overall transitionalCpG sites were not significantly different between the distinct histologic types of the $\mathrm{LOH}-\mathrm{H}$ cases (data not shown). When assuming that the methylation of transitional-CpG sites promotes cell differentiation, the $\mathrm{LOH}$ induced demethylation may lead to the dedifferentiation of gastric cancer cells. Therefore, the dynamic methylation pattern of transitional-CpG sites in a given gastric cancer appears to be determined according to the level of $\mathrm{LOH}$ rather than H. pylori infection and the differentiation state of cancer progenitor cells. 
The transitional-CpG sites containing repeat sequences with a low $\mathrm{CpG}$ content often limit the use of an adequate MSP primer set. The real-time PCR protocol, which has been adapted for the quantitative estimation of CpG-island methylation, shows weak or non-specific signals when amplifying the transitionalCpG sites [4]. Diverse experimental protocols have demonstrated that the results of PCR-based methylation analyses are variable between experimental samples, and the analyses fluctuate according to the PCR conditions even with examining the same tissue DNA [39] (Figure 2A and 2B). Especially, a high number of amplification cycles is prone to biased expansion of the methylation amplicon in the analysis of small biopsy tissues. The radioisotope-labeling PCR with a minimal number of amplification cycles is necessary for the PCR-DNA-band's sharpness and reproducibility. In this study, to ensure reliable experimental results, an intermediate level of methylation variation was determined based on the reproducibility and variation range of the MSP density, as was estimated using the duplicated same tissue and pairs of adjacent tissues and the antrum and body tissues (Figure 2).

\section{Conclusions}

According to the self-organization and dosage compensation models, several stomach-specific genes lacking CpG-islands and numerous housekeeping genes containing CpG-islands coordinate to establish gastric cell phenotypes in the newly fixed stem cells. This study suggests that the concurrent methylation of multiple CpG-island genes is initiated under the influence of nearby retroelement methylation in the gastric mucosa infected with $H$. pylori, and the $\mathrm{LOH}$-induced DNA demethylation and discordant methylation of stomachspecific genes may facilitate gastric carcinogenesis by reactivating a stem-cell intrinsic program.

\section{Additional material}

Additional file 1: List of MSP primer sets for the 14 transitional-CpG sites. We summarized the MSP sites, sequences, and conditions for the 14 transitional-CpG sites.

\section{Acknowledgements}

The study was supported by Catholic Institute of Cell therapy Basic Science Programs Foundation made in the program year of 2006; Grant number: 2006005041

\section{Author details}

'Department of Microbiology, College of Medicine, The Catholic University of Korea, Seoul, Korea. ${ }^{2}$ Department of Internal Medicine, College of Medicine, The Catholic University of Korea, Seoul, Korea. ${ }^{3}$ Department of Clinical Pathology, College of Medicine, The Catholic University of Korea, Seoul, Korea.

\section{Authors' contributions}

SJH conceptualized, helped with data collection and analysis, and drafted the manuscript. JHO and EJJ helped with performing the endoscopic biopsy and data collection. KOM helped with performing the histopathologic examination. MIK and SWC conceived the study, participated in its design and contributed to the manuscript. MGR conceptualized, edited the manuscript for important intellectual content and has read and approved the final version of the manuscript. All authors read and approved the final manuscript.

\section{Competing interests}

The authors declare that they have no competing interests.

Received: 2 July 2010 Accepted: 20 November 2010

Published: 20 November 2010

\section{References}

1. Houghton J, Stoicov C, Nomura S, Rogers AB, Carlson J, Li H, Cai X, Fox JG, Goldenring JR, Wang TC: Gastric cancer originating from bone marrowderived cells. Science 2004, 306(5701):1568-1571.

2. Misteli T: Beyond the sequence: cellular organization of genome function. Cell 2007, 128(4):787-800.

3. Birchler JA, Bhadra U, Bhadra MP, Auger DL: Dosage-dependent gene regulation in multicellular eukaryotes: implications for dosage compensation, aneuploid syndromes, and quantitative traits. Dev Biol 2001, 234(2):275-288

4. Hong SJ, Kang MI, Oh JH, Jung YC, Kim YH, Kim SJ, Choi SH, Seo EJ, Choi SW, Rhyu MG: DNA methylation and expression patterns of key tissue-specific genes in adult stem cells and stomach tissues. J Korean Med Sci 2009, 24(5):918-929.

5. Correa P, Houghton J: Carcinogenesis of Helicobacter pylori. Gastroenterology 2007, 133(2):659-672.

6. Van De Bovenkamp JH, Korteland-Van Male AM, Buller HA, Einerhand AW, Dekker J: Infection with Helicobacter pylori affects all major secretory cell populations in the human antrum. Dig Dis Sci 2005, 50(6):1078-1086

7. Park SY, Yoo EJ, Cho NY, Kim N, Kang GH: Comparison of CpG island hypermethylation and repetitive DNA hypomethylation in premalignant stages of gastric cancer, stratified for Helicobacter pylori infection. J Pathol 2009, 219(4):410-416.

8. Hong SJ, Oh JH, Jung YC, Kim YH, Kim SJ, Kang SJ, Seo EJ, Choi SW, Kang MI, Rhyu MG: DNA methylation patterns of ulcer-healing genes associated with the normal gastric mucosa of gastric cancers. J Korean Med Sci 2010, 25(3):405-417.

9. Medstrand P, van de Lagemaat LN, Mager DL: Retroelement distributions in the human genome: variations associated with age and proximity to genes. Genome Res 2002, 12(10):1483-1495.

10. Yoder JA, Walsh CP, Bestor TH: Cytosine methylation and the ecology of intragenomic parasites. Trends Genet 1997, 13(8):335-340.

11. Kang MI, Rhyu MG, Kim YH, Jung YC, Hong SJ, Cho CS, Kim HS: The length of $\mathrm{CpG}$ islands is associated with the distribution of Alu and L1 retroelements. Genomics 2006, 87(5):580-590.

12. Jung YC, Hong SJ, Kim YH, Kim SJ, Kang SJ, Choi SW, Rhyu MG: Chromosomal losses are associated with hypomethylation of the genecontrol regions in the stomach with a low number of active genes. J Korean Med Sci 2008, 23(6):1068-1089.

13. Kang Ml, Kim HS, Jung YC, Kim YH, Hong SJ, Kim MK, Baek KH, Kim CC, Rhyu MG: Transitional CpG methylation between promoters and retroelements of tissue-specific genes during human mesenchymal cell differentiation. J Cell Biochem 2007, 102(1):224-239.

14. Turker MS: Gene silencing in mammalian cells and the spread of DNA methylation. Oncogene 2002, 21(35):5388-5393.

15. Kim YH, Hong SJ, Jung YC, Kim SJ, Seo EJ, Choi SW, Rhyu MG: The 5'-end transitional $\mathrm{CpGs}$ between the $\mathrm{CpG}$ islands and retroelements are hypomethylated in association with loss of heterozygosity in gastric cancers. BMC Cancer 2006, 6:180,

16. Irizarry RA, Ladd-Acosta C, Wen B, Wu Z, Montano C, Onyango P, Cui H, Gabo K, Rongione M, Webster M, Ji H, Potash JB, Sabunciyan S, Feinberg AP: The human colon cancer methylome shows similar hypoand hypermethylation at conserved tissue-specific $\mathrm{CpG}$ island shores. Nat Genet 2009, 41(2):178-186. 
17. Xie H, Wang M, Bonaldo Mde F, Smith C, Rajaram V, Goldman S, Tomita T, Soares MB: High-throughput sequence-based epigenomic analysis of Alu repeats in human cerebellum. Nucleic Acids Res 2009, 37(13):4331-4340.

18. Hong SJ, Kim YH, Choi YD, Min KO, Choi SW, Rhyu MG: Relationship between the extent of chromosomal losses and the pattern of CpG methylation in gastric carcinomas. J Korean Med Sci 2005, 20(5):790-805.

19. Greene FL, American Joint Committee on Cancer., American Cancer Society: AJCC cancer staging manual. New York: Springer-Verlag; 62002.

20. Kim KM, Kwon MS, Hong SJ, Min KO, Seo EJ, Lee KY, Choi SW, Rhyu MG Genetic classification of intestinal-type and diffuse-type gastric cancers based on chromosomal loss and microsatellite instability. Virchows Arch 2003, 443(4):491-500.

21. Hong SJ, Choi SW, Lee KH, Lee S, Min KO, Rhyu MG: Preoperative genetic diagnosis of gastric carcinoma based on chromosomal loss and microsatellite instability. Int J Cancer 2005, 113(2):249-258.

22. Broutet N, Plebani M, Sakarovitch C, Sipponen P, Megraud F: Pepsinogen A, pepsinogen $C$, and gastrin as markers of atrophic chronic gastritis in European dyspeptics. Br J Cancer 2003, 88(8):1239-1247.

23. Leung WK, Yu J, Chan FK, To KF, Chan MW, Ebert MP, Ng EK, Chung SC, Malfertheiner P, Sung JJ: Expression of trefoil peptides (TFF1, TFF2, and TFF3) in gastric carcinomas, intestinal metaplasia, and non-neoplastic gastric tissues. J Pathol 2002, 197(5):582-588.

24. Demetter P, De Vos M, Van Damme N, Baeten D, Elewaut D, Vermeulen S, Mareel M, Bullock G, Mielants H, Verbruggen G, De Keyser F, Veys EM, Cuvelier CA: Focal up-regulation of E-cadherin-catenin complex in inflamed bowel mucosa but reduced expression in ulcer-associated cell lineage. Am J Clin Pathol 2000, 114(3):364-370.

25. Lee JH, Park SJ, Abraham SC, Seo JS, Nam JH, Choi C, Juhng SW, Rashid A, Hamilton SR, Wu TT: Frequent CpG island methylation in precursor lesions and early gastric adenocarcinomas. Oncogene 2004, 23(26):4646-4654.

26. Konturek PC, Brzozowski T, Kania J, Konturek SJ, Kwiecien S, Pajdo R, Hahn EG: Pioglitazone, a specific ligand of peroxisome proliferatoractivated receptor-gamma, accelerates gastric ulcer healing in rat. Eur $J$ Pharmacol 2003, 472(3):213-220.

27. Sato F, Meltzer SJ: CpG island hypermethylation in progression of esophageal and gastric cancer. Cancer 2006, 106(3):483-493.

28. Knoll B, Goldammer M, Wojewoda A, Flugge J, Johne A, Mrozikiewicz PM, Roots I, Kopke K: An anomalous haplotype distribution of the arrestin domain-containing 4 gene (ARRDC4) haplotypes in Caucasians. Genet Test 2008, 12(1):147-152.

29. Owens DM, Keyse SM: Differential regulation of MAP kinase signalling by dual-specificity protein phosphatases. Oncogene 2007, 26(22):3203-3213.

30. Zhang $Q H, Y e ~ M, W u X Y$, Ren SX, Zhao M, Zhao CJ, Fu G, Shen Y, Fan HY, Lu G, Zhong M, Xu XR, Han ZG, Zhang JW, Tao J, Huang QH, Zhou J, $\mathrm{Hu}$ GX, Gu J, Chen SJ, Chen Z: Cloning and functional analysis of cDNAs with open reading frames for 300 previously undefined genes expressed in CD34+ hematopoietic stem/progenitor cells. Genome Res 2000, 10(10):1546-1560.

31. Frierson HF, Moskaluk CA, Powell SM, Zhang H, Cerilli LA, Stoler MH, Cathro H, Hampton GM: Large-scale molecular and tissue microarray analysis of mesothelin expression in common human carcinomas. Hum Pathol 2003, 34(6):605-609.

32. Camilo R, Capelozzi VL, Siqueira SA, Del Carlo Bernardi F: Expression of p63, keratin 5/6, keratin 7, and surfactant-A in non-small cell lung carcinomas. Hum Pathol 2006, 37(5):542-546.

33. Tusnady GE, Simon I, Varadi A, Aranyi T: BiSearch: primer-design and search tool for PCR on bisulfite-treated genomes. Nucleic Acids Res 2005 33(1):e9.

34. Boumber YA, Kondo Y, Chen X, Shen L, Guo Y, Tellez C, Estecio MR, Ahmed S, Issa JP: An Sp1/Sp3 binding polymorphism confers methylation protection. PLoS Genet 2008, 4(8):e1000162.

35. Hemberger M, Dean W, Reik W: Epigenetic dynamics of stem cells and cell lineage commitment: digging Waddington's canal. Nat Rev Mol Cell Biol 2009, 10(8):526-537.

36. Ferretti C, Bruni L, Dangles-Marie V, Pecking AP, Bellet D: Molecular circuits shared by placental and cancer cells, and their implications in the proliferative, invasive and migratory capacities of trophoblasts. Hum Reprod Update 2007, 13(2):121-141.
37. Yatabe $Y$, Tavare S, Shibata D: Investigating stem cells in human colon by using methylation patterns. Proc Natl Acad Sci USA 2001, 98(19):10839-10844.

38. Wood LD, Parsons DW, Jones S, Lin J, Sjoblom T, Leary RJ, Shen D, Boca SM, Barber T, Ptak J, Silliman N, Szabo S, Dezso Z, Ustyanksky V, Nikolskaya T, Nikolsky Y, Karchin R, Wilson PA, Kaminker JS, Zhang Z, Croshaw R, Willis J, Dawson D, Shipitsin M, Willson JK, Sukumar S, Polyak K, Park BH, Pethiyagoda CL, Pant PV, et al: The genomic landscapes of human breast and colorectal cancers. Science 2007, 318(5853):1108-1113.

39. Shen L, Guo Y, Chen X, Ahmed S, Issa JP: Optimizing annealing temperature overcomes bias in bisulfite PCR methylation analysis. Biotechniques 2007, 42(1):48-58

\section{Pre-publication history}

The pre-publication history for this paper can be accessed here: http://www.biomedcentral.com/1471-230X/10/137/prepub

doi:10.1186/1471-230X-10-137

Cite this article as: Hong et al:: The overmethylated genes in Helicobacter pylori-infected gastric mucosa are demethylated in gastric cancers. BMC Gastroenterology 2010 10:137.

\section{Submit your next manuscript to BioMed Central and take full advantage of:}

- Convenient online submission

- Thorough peer review

- No space constraints or color figure charges

- Immediate publication on acceptance

- Inclusion in PubMed, CAS, Scopus and Google Scholar

- Research which is freely available for redistribution

Submit your manuscript at www.biomedcentral.com/submit
Biomed Central 